05

\title{
Откол в сапфире при ударном сжатии в различных кристаллографических направлениях
}

\author{
(C) И.А. Черепанов, ${ }^{1,2}$ A.С. Савиных, ${ }^{1, \uparrow}$, С.В. Разоренов ${ }^{1,2}$ \\ ${ }^{1}$ Институт проблем химической фризики РАН, \\ 142432 Черноголовка, Россия \\ ${ }^{2}$ Московский государственный университет им. М.В. Ломоносова, \\ 119991 Москва, Россия \\ T e-mail: savas@ficp.ac.ru
}

Поступило в Редакцию 19 ноября 2019г.

В окончательной редакции 19 ноября 2019г.

Принято к публикации 26 декабря 2019г.

\begin{abstract}
Представлены результаты измерений прочности на разрыв монокристаллов сапфира 8 кристаллографических ориентаций $c, a, d, r, n, s, g$ и $m$ в диапазоне ударного сжатия $15-20 \mathrm{GPa}$. Выявлена зависимость откольной прочности от направления удара и максимального напряжения сжатия. Наиболее высокие значения откольной прочности $\sim 12-13 \mathrm{GPa}$ реализуются при максимальном напряжении ударного сжатия $16 \mathrm{GPa}$ в образцах монокристаллического сапфира ориентаций $m$ и $a$.
\end{abstract}

Ключевые слова: сапфир, откольная прочность, ударные волны.

DOI: $10.21883 /$ JTF.2020.06.49283.368-19

\section{Введение}

Сапфир обладает целым рядом уникальных физических и химических свойств [1], таких как высокая механическая прочность и твердость, является оптически прозрачным материалом в широком диапазоне спектра и рабочих температур и давлений, способен работать в агрессивных средах, в условиях воздействия радиации и высоких температур. Результаты исследований механических свойств сапфира при ударных нагрузках представлены в работах [2-7]. В частности, в исследовании [2] приведены результаты экспериментов с монокристаллами сапфира при сжатии в различных кристаллографических направлениях. Показана зависимость динамического предела упругости (Hugoniot Elastic Limit, $\left.\sigma_{H E L}\right)$ от кристаллографического направления и величины давления ударного сжатия.

Для практических приложений особое значение имеет сохранение оптической прозрачности и однородности монокристаллического сапфира в широком диапазоне интенсивностей ударных воздействий. Известно, что его прозрачность нарушается при напряжениях ударного сжатия близких к динамическому пределу упругости и меняется с длительностью приложенной нагрузки [8]. При этом регистрируется люминесценция ударносжатого сапфира, имеющая выраженный гетерогенный характер [9]. Эксперименты по измерению критических разрушающих напряжений (откольной прочности) сапфира при динамическом нагружении проводились на образцах с отдельными ориентациями и не носили систематический характер. Так, например, в работе по изучению откольной прочности сапфира ориентации c [10] было зафиксировано, что в области упругого деформирования сапфир демонстрирует чрезвычайно высокие значения разрушающих напряжений при отколе, возрастающие с уменьшением длительности нагрузки, а с началом пластического деформирования прочность на разрыв падает практически до нуля.

В настоящей работе с целью оценки анизотропии откольной прочности сапфира проведены измерения и анализ профилей скорости контактной поверхности монокристалла сапфира 8 кристаллографических ориентаций.

\section{Материал и постановка экспериментов}

Исследуемые образцы монокристаллического сапфира плотностью $3.97 \mathrm{~g} / \mathrm{cm}^{3}$ представляли собой диски толщиной $5 \mathrm{~mm}$ и диаметром 22 или $50 \mathrm{~mm}$. В таблице приведены соответствующие значения угла $\Theta$ между осью, вдоль которой проводилось нагружение образца и главной осью сапфира $c$, а также измеренные значения продольной скорости звука $c_{l}$.

Нагружение образцов монокристаллического сапфира осуществлялось ударом алюминиевой пластины толщиной $0.4 \mathrm{~mm}$, разогнанной до скоростей $1.2 \pm 0.05$, $1.3 \pm 0.05$ и $1.55 \pm 0.05 \mathrm{~km} / \mathrm{s}$ с использованием взрывных устройств [11], что соответствует максимальному расчетному напряжению ударного сжатия $\sim 15, \sim 16.5$ и $\sim 20 \mathrm{GPa}$. Эксперименты были организованы так, что во всех случаях в образцах сапфира реализовывались условия откольного разрушения. Поперечные размеры всех образцов были достаточны для обеспечения условия одномерной деформации в течение всего времени регистрации. Для отсечения воздушной волны, которая образуется перед летящим ударником, нагружение образца проводилось через алюминиевый экран толщиной 


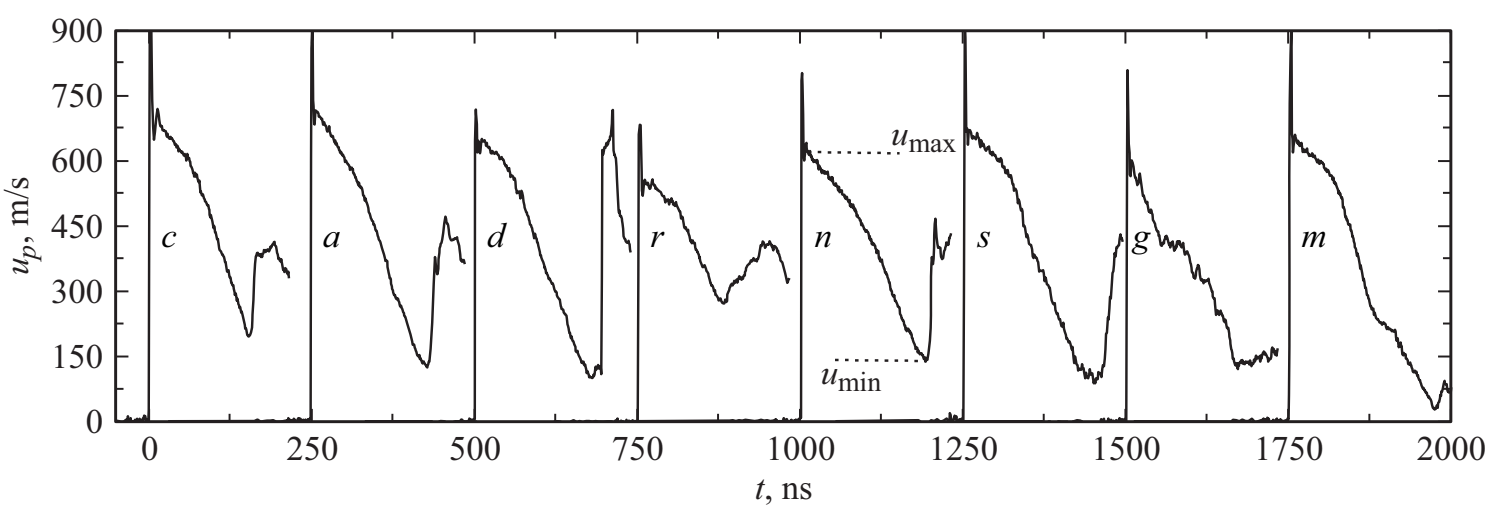

Рис. 1. Профили скорости контактной поверхности образцов монокристалла сапфира ориентаций $c, a, d, r, n, s, g$ и $m$ при максимальном напряжении сжатия $\sim 16.5 \mathrm{GPa}$.

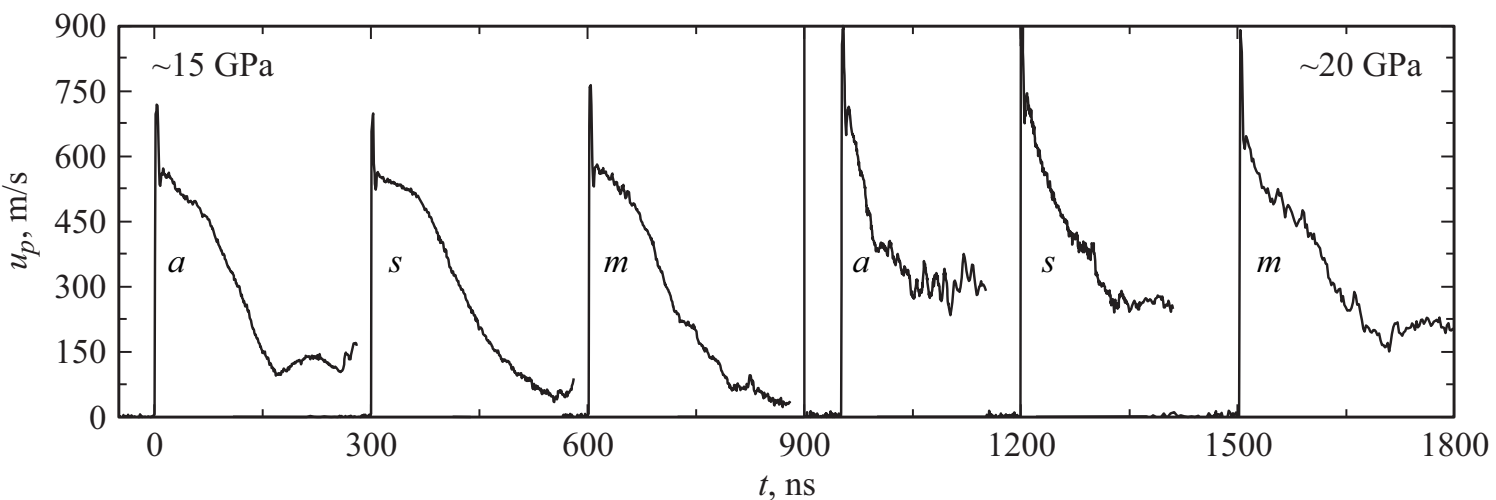

Рис. 2. Профили скорости контактной поверхности образцов монокристалла сапфира ориентаций $a, s$ и $m$ при максимальном напряжении сжатия $\sim 15$ и $\sim 20 \mathrm{GPa}$.

$2 \mathrm{~mm}$. Во всех экспериментах с помощью лазерного доплеровского измерителя скорости VISAR [12], имеющего в использовавшейся конфигурации временное разрешение $\sim 0.8 \mathrm{~ns}$, регистрировались профили скорости контактной поверхности $u_{p}(t)$ между образцом и водяным окном. Для отражения лазерного излучения на поверхность образца наклеивалась алюминиевая фольга толщиной $10 \mu \mathrm{m}$.

\section{Результаты измерений}

На рис. 1 представлены профили скорости контактной поверхности образцов сапфира 8 ориентаций при ударе со скоростью $1.3 \mathrm{~km} / \mathrm{s}$. Во всех экспериментах регистрируется выход на поверхность упругой волны сжатия, следующей за ней волны разрежения и откол. Кратковременный „выброс“ скорости на фронте ударного импульса сжатия связан с тем, что алюминиевая фольга обладает меньшим динамическим импедансом, поэтому после выхода ударной волны на контактную поверхность приобретает более высокую скорость, чем поверхность сапфира. В дальнейшем скорости выравниваются из-за противодавления со стороны воды.
В экспериментах с ориентациями образцов $g$ и $r$ (в отличие от остальных направлений) регистрируются меньшие значения максимальной скорости контактной поверхности. Возможно, в этих экспериментах был превышен динамический предел упругости, и по мере распространения упругопластической волны сжатия произошла релаксация напряжений до величины $\sigma_{H E L}$ и, таким образом, откольное разрушение происходило в упругой области деформирования. Согласно работе [2], динамический предел упругости образцов ориентации g составляет $13-16 \mathrm{GPa}$, ориентации $r \sim 13 \mathrm{GPa}$. Эти значения близки к максимальным напряжениям сжатия в проведенных экспериментах с образцами ориентации $g$ и $r$, что подтверждает сделанное предположение.

Детальный анализ полученных волновых профилей, представленных на рис. 1, выявляет анизотропию в эволюции формы волны разрежения и формы откольного импульса. За исключением ориентации $g$ во всех остальных случаях наблюдается резкий второй подъем скорости, связанный с образованием откольного импульса в момент разрушения образца. Измеренное время формирования откольного импульса для образцов ориентаций $d, c, a, n$ составило $1.6-8 \mathrm{~ns}$, что свидетельствует о чрезвычайно быстром развитии процесса разрушения. 
Результаты измерений продольной скорости звука $c_{l}$ при нулевом давлении и откольной прочности $\sigma_{s p}$ в зависимости от максимального напряжения сжатия $\sigma_{\max }$

\begin{tabular}{|c|c|c|c|c|c|c|c|c|}
\hline Ориентация & $\begin{array}{c}c \\
(0001)\end{array}$ & $\begin{array}{c}a \\
(11 \overline{2} 0)\end{array}$ & $\begin{array}{c}d \\
(10 \overline{1} 4)\end{array}$ & $\begin{array}{c}r \\
\left(1 \frac{1}{1} 02\right)\end{array}$ & $\begin{array}{c}n \\
(11 \overline{2} 3)\end{array}$ & $\begin{array}{c}s \\
(10 \overline{1} 1)\end{array}$ & 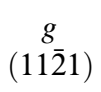 & $\begin{array}{c}m \\
(10 \overline{1} 0)\end{array}$ \\
\hline $\begin{array}{c}\Theta,{ }^{\circ} \\
c_{l}, \mathrm{~km} / \mathrm{s}\end{array}$ & $\begin{array}{c}0 \\
11.21\end{array}$ & $\begin{array}{c}90 \\
11.23\end{array}$ & $\begin{array}{c}38 \\
10.95\end{array}$ & $\begin{array}{c}57 \\
10.60\end{array}$ & $\begin{array}{c}61 \\
10.85\end{array}$ & $\begin{array}{c}72 \\
11.20\end{array}$ & $\begin{array}{c}79 \\
11.11\end{array}$ & $\begin{array}{c}90 \\
1121\end{array}$ \\
\hline \multicolumn{9}{|c|}{$\sim 15 \mathrm{GPa}$} \\
\hline $\begin{array}{l}\sigma_{s p}, \mathrm{GPa} \\
\sigma_{\max } \mathrm{GPa}\end{array}$ & $\begin{array}{l}- \\
-\end{array}$ & $\begin{array}{r}9.8 \\
13.4\end{array}$ & $\begin{array}{l}- \\
-\end{array}$ & - & - & $\begin{array}{r}9.6 \\
13.2\end{array}$ & $\begin{array}{l}- \\
-\end{array}$ & $\begin{array}{l}11.6 \\
13.7\end{array}$ \\
\hline \multicolumn{9}{|c|}{$\sim 16 \mathrm{GPa}$} \\
\hline $\begin{array}{c}\sigma_{s p}, \mathrm{GPa} \\
\sigma_{\max } \mathrm{GPa}\end{array}$ & $\begin{array}{l}10.6 \\
17.3\end{array}$ & $\begin{array}{l}12.1 \\
17.2\end{array}$ & $\begin{array}{l}11.3 \\
15.4\end{array}$ & $\begin{array}{r}5.1 \\
12.8\end{array}$ & $\begin{array}{r}9.9 \\
14.9\end{array}$ & $\begin{array}{l}11.9 \\
16.2\end{array}$ & $\begin{array}{r}9.7 \\
14.4\end{array}$ & $\begin{array}{l}13.1 \\
15.7\end{array}$ \\
\hline \multicolumn{9}{|c|}{$\sim 20 \mathrm{GPa}$} \\
\hline $\begin{array}{c}\sigma_{s p}, \mathrm{GPa} \\
\sigma_{\max } \mathrm{GPa}\end{array}$ & $\begin{array}{c}8.9-10.6 \\
{[11]} \\
18\end{array}$ & $\begin{array}{c}8.3 \\
17.3\end{array}$ & - & - & - & 17.9 & - & 10.1 \\
\hline
\end{tabular}

Для образцов других ориентаций время нарастания параметров во фронте откольного импульса находится в диапазоне от 14 до 130 ns. Появление нерегулярных осцилляций на всех профилях контактной поверхности после откольного разрушения свидетельствует о появлении и распространении микротрещин и разрушении откольной пластины.

Значения растягивающих напряжений непосредственно перед разрушением (откольной прочности) сапфира рассчитывались методом характеристик по измеренным значениям массовой скорости в максимуме $u_{\max }$ и перед фронтом откольного импульса $u_{\text {min }}$ с учетом водяного окна [11]. Ударная сжимаемость сапфира в области упругого деформирования измерялась только для ориентации c [9], для которой получено выражение для ударной адиабаты в виде $U_{S}=c_{l}+u_{p}$, где $U_{S}, u_{p}$ - скорость фронта упругой ударной волны и массовая скорость за фронтом, равная $u_{\max }$, соответственно, $c_{l}-$ продольная скорость звука при нулевом давлении (см. таблицу). Для остальных ориентаций в расчетах волновых отражений использовались аналогичные выражения для ударной адиабаты с соответствующими значениями $c_{l}$. При расчете напряжений и массовых скоростей в области растяжения использовалась экстраполяция ударной адиабаты в область отрицательных напряжений. Полученные значения откольной прочности $\sigma_{s p}$, а также рассчитанные из измеренных профилей контактной поверхности значения максимального напряжения сжатия $\sigma_{\max }$ суммированы в таблице .

Чтобы оценить зависимость величины $\sigma_{s p}$ от максимального напряжения сжатия, были проведены эксперименты с образцами ориентаций $a, s$ и $m$, демонстрирующие при скорости удара $1.3 \mathrm{~km} / \mathrm{s}$ наибольшие значения прочности на разрыв, при скоростях соударения 1.2 и $1.55 \mathrm{~km} / \mathrm{s}$. На рис. 2 представлены профили скорости контактной поверхности образцов $a, s$ и $m$ ориентаций при $\sigma_{\max } \sim 15$ и $\sim 20 \mathrm{GPa}$. При $\sigma_{\max } \sim 15 \mathrm{GPa}$ профили скорости контактной поверхности подобны полученным ранее при $16.5 \mathrm{GPa}$, за исключением того, что откольный импульс в экспериментах с образцами ориентации $m$ не регистрируется, в образцах $s$-ориентации время нарастания скорости в откольном импульсе увеличилось до $\sim 100 \mathrm{~ns}$, а в образцах ориентации а наблюдается слабо выраженный откольный импульс. При максимальном напряжении $\sim 20 \mathrm{GPa}$ профили контактной поверхности демонстрируют меньшую скорость, чем ожидалось. Этот эффект связан с тем, что в этих экспериментах максимальное напряжение сжатия превышает динамический предел упругости сапфира, и в процессе нагружения происходит релаксация напряжений на фронте ударной волны до значения $\sigma_{H E L}$, т.е. откольное разрушение происходит в упругой области. Во всех случаях при этом давлении ударного сжатия на волновых профилях наблюдается отсутствие откольных импульсов. Изменилась форма волны разрежения, ее длительность уменьшилась в 2-2.5 раза и в разгрузочной части импульса появились нерегулярные осцилляции.

\section{Заключение}

Проведены измерения откольной прочности монокристаллов сапфира 8 кристаллографических ориентаций $c, a, d, r, n, s, g$ и $m$ в диапазоне ударного сжатия 15-20 GPa. Максимальные значения критических разрушающих напряжений при отколе $\sigma_{s p} \sim 12-13 \mathrm{GPa}$ достигаются при давлении ударного сжатия $16 \mathrm{GPa}$ и реализуются при ударе в направлении $\mathrm{m}$ перпендикулярно призматической плоскости и в направлении $a$, когда ось перпендикулярна основной плоскости поверх- 
ности. Наименьшее значение критических разрушающих напряжений $\sim 5 \mathrm{GPa}$ зарегистрировано у сапфира $r$-ориентации. Величина откольной прочности образцов остальных исследованных ориентаций находится в диапазоне 9-11 GPa. Анизотропия эволюции ударной волны проявляется также в изменении формы откольного импульса. В образцах $d$-, $c$-, $a$-, $n$-ориентаций наблюдается чрезвычайно быстрый откол - время образования откольной трещины составило 1.6-8 ns. Для образцов других ориентаций этот параметр лежит в диапазоне от 14 до130 ns.

\section{Финансирование работы}

Работа выполнена в рамках Государственного задания по теме № 0089-2019-0001, № государственной регистрации ААА-А19-119071190040-5 с использованием оборудования Московского регионального взрывного Центра коллективного пользования.

\section{Конфликт интересов}

Авторы заявляют, что у них нет конфликта интересов.

\section{Список литературы}

[1] Dobrovinskaya E., Lytvynov L., Pischik V. Sapphire in science and engineering. Kharkiv: „STC Institute for Single Crystals“, 2007. $480 \mathrm{p}$.

[2] Kanel G.I., Nellis W.J., Savinykh A.S., Razorenov S.V., Rajendran A.M. // J. Appl. Phys. 2009. Vol. 106. P. 043524. DOI: $10.1063 / 1.3204940$

[3] Nowak R., Manninen T., Heiskanen K., Sekino T. // Appl. Phys. Lett. 2004. Vol. 83. N 25. P. 5214-5216.

DOI: $10.1063 / 1.1635983$

[4] Voloshyn O.V., Lytvynov L.A., Slyunin E.V. // Funct. Mater. 2007. Vol. 14. N 4. P. 569-572.

[5] Синани А.Б., Кожушко А.А., Зильбербранд Е.Л. // Письма в ЖТФ. 2008. Т. 34. Вып. 3. С. 27-31. [Sinani A.B., Kozhushko A.A., Zilberbrand E.L. // Tech. Phys. Lett. 2008. Vol. 34. N 2. P. 103-105. DOI: 10.1134/S1063785008020053]

[6] Wang Y., Mikkola D.E. // Mater. Sci. Eng. A. 1991. Vol. 148. N 1 P. 25-32. DOI: 10.1016/0921-5093(91)90862-H

[7] Reinhart W.D., Chhabildas L.C., Vogler T.J. // Int. J. Imp. Eng. 2006. Vol. 33. P. 655-669. DOI: 10.1016/j.ijimpeng.2006.09.083

[8] Barker L.M., Hollenbach R.E. // J. Appl. Phys. 1970. Vol. 41. P. 4208-4226. DOI: $10.1063 / 1.1658439$

[9] Hare D.E., Holmes N.C., Webb D.J. // Phys. Rev. B. 2002. Vol. 66. P. 014108. DOI: 10.1103/PhysRevB.66.014108

[10] Савиных А.С., Канель Г.И., Разоренов С.В. // Письма в ЖТФ. 2011. Т. 37. Вып. 7. С. 8-15. [Savinykh A.S., Kanel G.I., Razorenov S.V. // Tech. Phys. Lett. 2011. Vol. 37. N 4. P. 294-297. DOI: 10.1134/S1063785011040146]

[11] Канель Г.И., Разоренов С.В., Уткин А.В., Фортов В.Е. Ударно-волновые явления в конденсированных средах. М: Янус-К, 1996. $407 \mathrm{c}$.

[12] Barker L.M., Hollenbach R.E. // J. Appl. Phys. 1972. Vol. 43. P. 4669-4675. DOI: $10.1063 / 1.1660986$ 